STUDI

FRANCESI

\section{Studi Francesi}

Rivista quadrimestrale fondata da Franco Simone

185 (LXII | II) | 2018

OCTAVE MIRBEAU: UNE CONSCIENCE AU TOURNANT

DU SIEECLE - sous la direction de Ida Merello

\title{
RAPHAËL CONFIANT, L'insurrection de l'âme. Frantz Fanon, vie et mort du guerrier-silex
}

\section{Elena Fermi}

\section{OpenEdition}

\section{Journals}

Édition électronique

URL : https://journals.openedition.org/studifrancesi/14219

DOI : $10.4000 /$ studifrancesi. 14219

ISSN : 2421-5856

Éditeur

Rosenberg \& Sellier

Édition imprimée

Date de publication : 1 août 2018

Pagination : 377

ISSN : 0039-2944

\section{Référence électronique}

Elena Fermi, « RAPHAËL CONFIANT, L'insurrection de l'âme. Frantz Fanon, vie et mort du guerrier-silex », Studi Francesi [En ligne], 185 (LXII | II) | 2018, mis en ligne le 01 août 2018, consulté le 15 novembre 2021. URL : http://journals.openedition.org/studifrancesi/14219; DOI : https://doi.org/10.4000/ studifrancesi. 14219

Ce document a été généré automatiquement le 15 novembre 2021.

\section{(c)}

Studi Francesi è distribuita con Licenza Creative Commons Attribuzione - Non commerciale - Non opere derivate 4.0 Internazionale. 


\title{
RAPHAËL CONFIANT, L'insurrection de l'âme. Frantz Fanon, vie et mort du guerrier-silex
}

\author{
Elena Fermi
}

\section{RÉFÉRENCE}

RAPHAËL CONFIANT, L'insurrection de l'âme. Frantz Fanon, vie et mort du guerrier-silex, Lamentin (Martinique), Caraibéditions, 2017, 392 pp.

C'est la vie brève mais pleinement vécue de Frantz Fanon (1925-1961), le guerrier-silex selon la définition d'Aimé Césaire, que Raphaël confIANT évoque dans cette autobiographie imaginée du médecin et essayiste martiniquais. Une vie brusquement interrompue par une leucémie myéloïde qui le frappa alors qu'il n'avait que trente-six ans mais qui aurait pu se terminer même avant pour cet engagé dans la lutte anticolonialiste pour l'indépendance de l'Algérie dans les rangs du FLN, collaborateur de la célèbre Wilaya IV, rédacteur du journal «El-Moudjahid» et membre du GPRA, rescapé à plusieurs attentats organisés pour l'éliminer. confiant consacre au psychiatre et militant révolutionnaire, auteur des célèbres Peau noire, masques blancs et des Damnés de la terre, un ouvrage passionnant, qui regorge de références et de détails historiques. Alternant récit autobiographique et mise en perspective d'un parcours hors du commun, l'auteur construit un ouvrage mosaïque qui permet de revenir sur toutes les étapes de l'itinéraire de Fanon. Un ouvrage qui se lit presque comme un roman, dans lequel on se promène temporellement et géographiquement pendant une trentaine d'années. Confiant alterne la première et la troisième personne sans souci de respecter la chronologie des événements dans un récit qui passe du passé au présent au sein d'un même chapitre où des crochets mettent parfois en valeur un thème, une anecdote. On suit l'itinéraire de Fanon de sa Martinique natale à la France, où il s'engage pendant la Seconde Guerre mondiale avec les Forces Françaises Libres et où il étudie ensuite la 
médecine à Lyon, puis à l'Algérie, où il exerce en tant que psychiatre à l'hôpital de Blida-Joinville, qui va devenir sa patrie d'adoption et où il demandera d'être enterré, jusqu'à l'hôpital de Bethesda aux États-Unis où il terminera ses jours en 1961. Derrière le militant révolutionnaire, on découvre le médecin novateur en matière de psychiatrie adaptée aux situations coloniales, l'humaniste qui théorise dans ses essais l'aliénation de l'homme noir suite à la colonisation, l'homme aux identités multiples, martiniquaise, française et algérienne. Un être aux multiples facettes, engagé toute sa vie durant, un homme de pensée et d'action, intransigeant face à l'inacceptable, un humaniste qui n'envisageait cependant pas autre chose que la lutte armée pour mener à bien la décolonisation. 